\title{
Family policies in Europe: available databases and initial comparisons
}

\author{
Olivier Thévenon*
}

\begin{abstract}
Population trends in recent years have prompted most European countries to introduce or expand family support policies. In particular, the decline in fertility since the 1970s might be harmful in the long term. The number of children per family is often below the desired number declared in surveys. State support is intended to close the gap by lowering the barriers to having children. The increase in divorce, separation and blended families, and the numbers of children born outside marriage and living with 'lone' parents, have also prompted countries to increase support for families, particularly for struggling families, whose children are the most vulnerable to poverty. At the same time, governments have sought to encourage women's workforce participation by ensuring that these policies enable parents to strike a better balance between work and family. Consequently, the total investment of governments in benefits and services for families has strongly increased recently, reaching an average of $2.4 \%$ of GDP in 2003 in OECD countries, compared with $1.6 \%$ in 1980 .
\end{abstract}

\section{Women's workforce participation and fertility: reconciled objectives?}

Family policies vary considerably from one country to another. Some countries have long-standing family policies that have continuously developed ever since they were introduced to counteract new risks for families. Other countries have introduced family policies more recently and these still consist of a disparate set of welfare measures.

Countries also have different objectives, with stated priorities ranging from support for fertility, support for the work/family balance, reducing inequality in living standards or reducing family poverty, to support for children's healthcare

\footnotetext{
* Olivier Thévenon, Institut national d'études démographiques, 133 Boulevard Davout, 75980 Paris Cedex 20, France. Email: olivier.thevenon@ined.fr. The author alone is responsible for the opinions expressed in this paper.
} 
or education, or promotion of a more equitable division of family care between men and women.

The two objectives of expanding women's workforce participation and increasing fertility were long considered at odds with each other. But the negative correlation which was observed between female employment and fertility rates in the early 1980s no longer exists - it even turned positive in the 2000s (Figure 1). In fact, fertility rates are highest in those countries where the proportion of women in the workforce is also highest. That is because public policies play a role in reconciling these seemingly incompatible objectives. However, the resources available to families for integrating work and family are different from country to country. The types of government support vary according to the emphasis placed on the family, the division of labour between men and women, and the labour market (Esping-Andersen 1999; Thévenon 2006; Neyer 2006; Meulders and O’Dorchai 2007).

Figure 1:

Total fertility rate and women's workforce participation rate in OECD countries in 2005

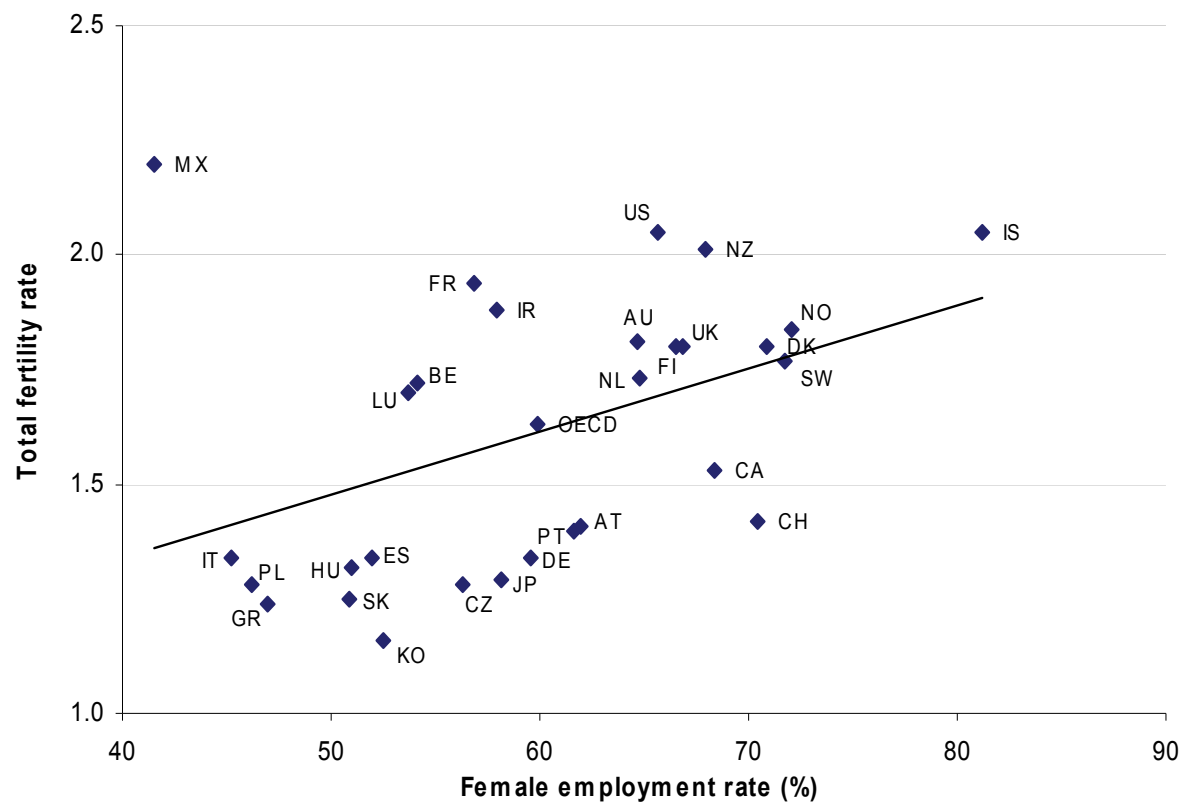

AU: Australia, AT: Austria, BE: Belgium, CA: Canada, CH: Switzerland, CZ: Czech Republic, KO: Korea, DE: Germany, DK: Denmark, ES: Spain, FI: Finland, FR: France, GR: Greece, HU: Hungary, IR: Ireland, IS: Iceland, IT: Italy, JP: Japan, KO: Korea, LU: Luxembourg, MX: Mexico, NL: Netherlands, NO: Norway, OECD: all OECD countries, PL: Poland, PT: Portugal, SK: Slovakia, SW: Sweden, UK: United Kingdom, US: United States of America. 


\section{Varied development of family support policies in Europe}

To study these differences in policy, several databases have been created (see Appendix for a presentation of different available databases). The most recent is the Family Database developed at the OECD in 2006 (http://www.oecd.org/els/social/family/database). This dataset currently covers OECD countries, and ultimately all EU member countries should also be included. It contains socio-demographic contextual data as well as indicators on support programmes, allowing comparisons of different configurations of family policies, their context and their outcomes. In particular, the indicators make it possible to compare policies on parental leave, child care and education facilities and financial support. This information is also rounded out by macro-data on the structure of families, fertility indicators and the impact of having children on employment and on child welfare. Family policies can thus be compared in relation to the context in which they are implemented (Thévenon 2007). The results of an initial exploitation of this database make it possible to describe the key differences in terms of support for working parents with young children.

A principal component analysis (PCA) of the OECD data makes it possible to identify the main similarities and differences in family policies between European countries (Thévenon 2008). The variables included in the analysis are all described in Table 1. (Note that Table 1 shows all the data in the analysis but not all the countries.) Apart from European countries, several other OECD countries were included: Anglo-Saxon countries (USA, Australia, New Zealand) and Asian countries (Japan and Korea). Figure 2 represents the countries' positioning according to that analysis. The analysis confirms the contrasts highlighted by previous studies (Gornick et al. 1997; Gauthier 2002; De Hénau et al. 2006). The more detailed data available in this database make it possible to highlight heterogeneity within given groups of countries. Some countries exhibit characteristics that are quite different from their geographical neighbours. 


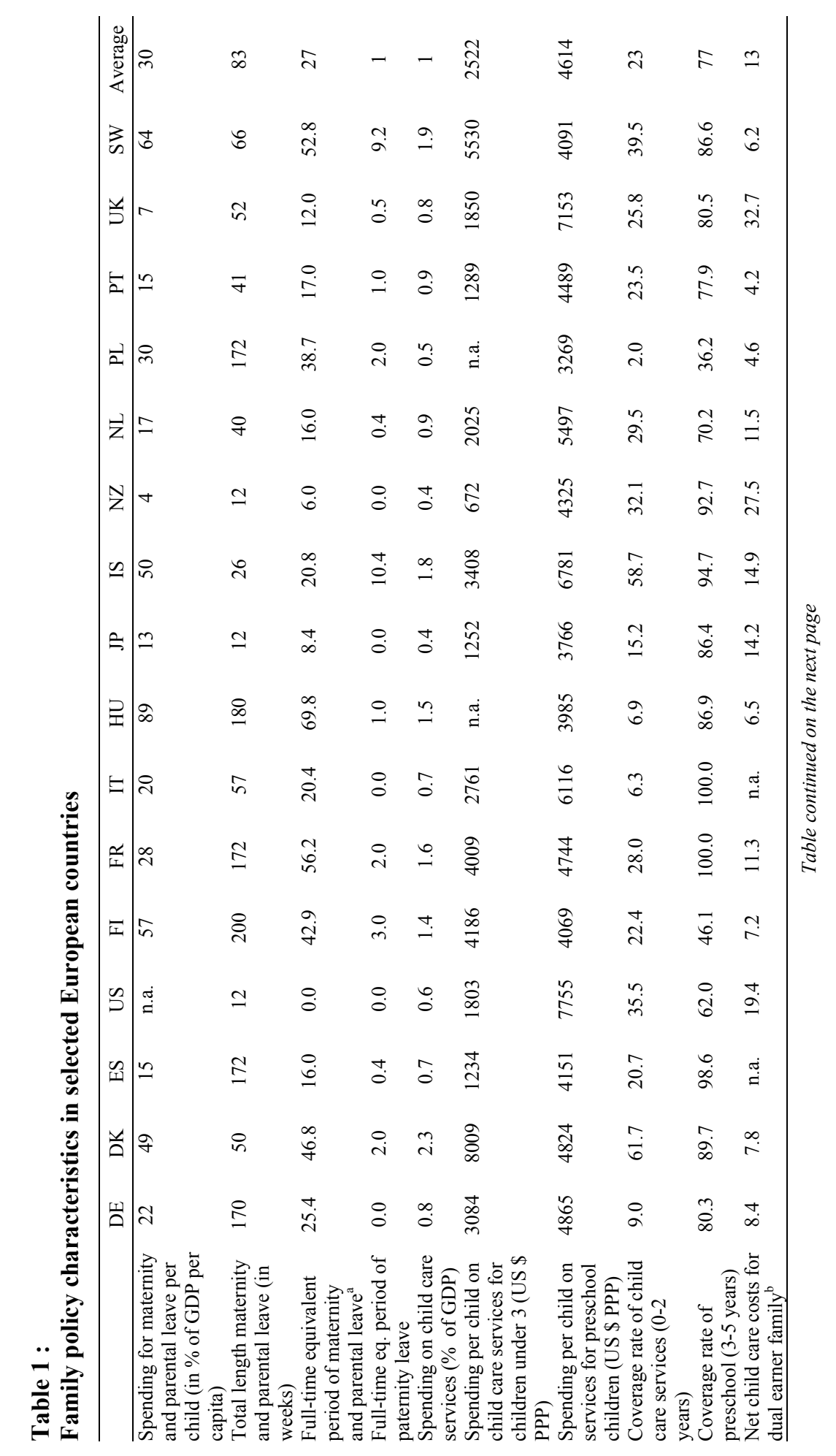




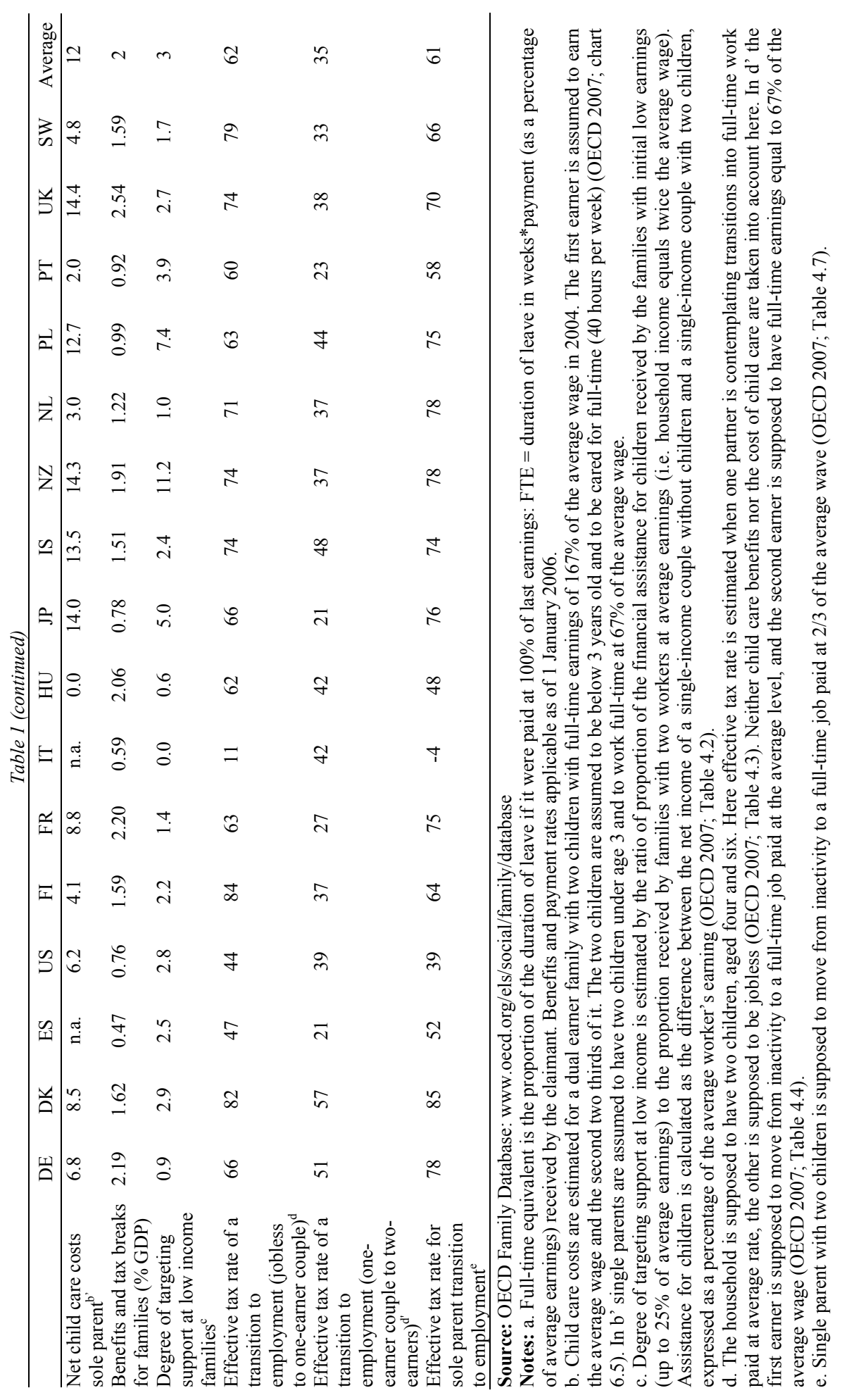


Figure 2:

OECD countries according to patterns of family policies

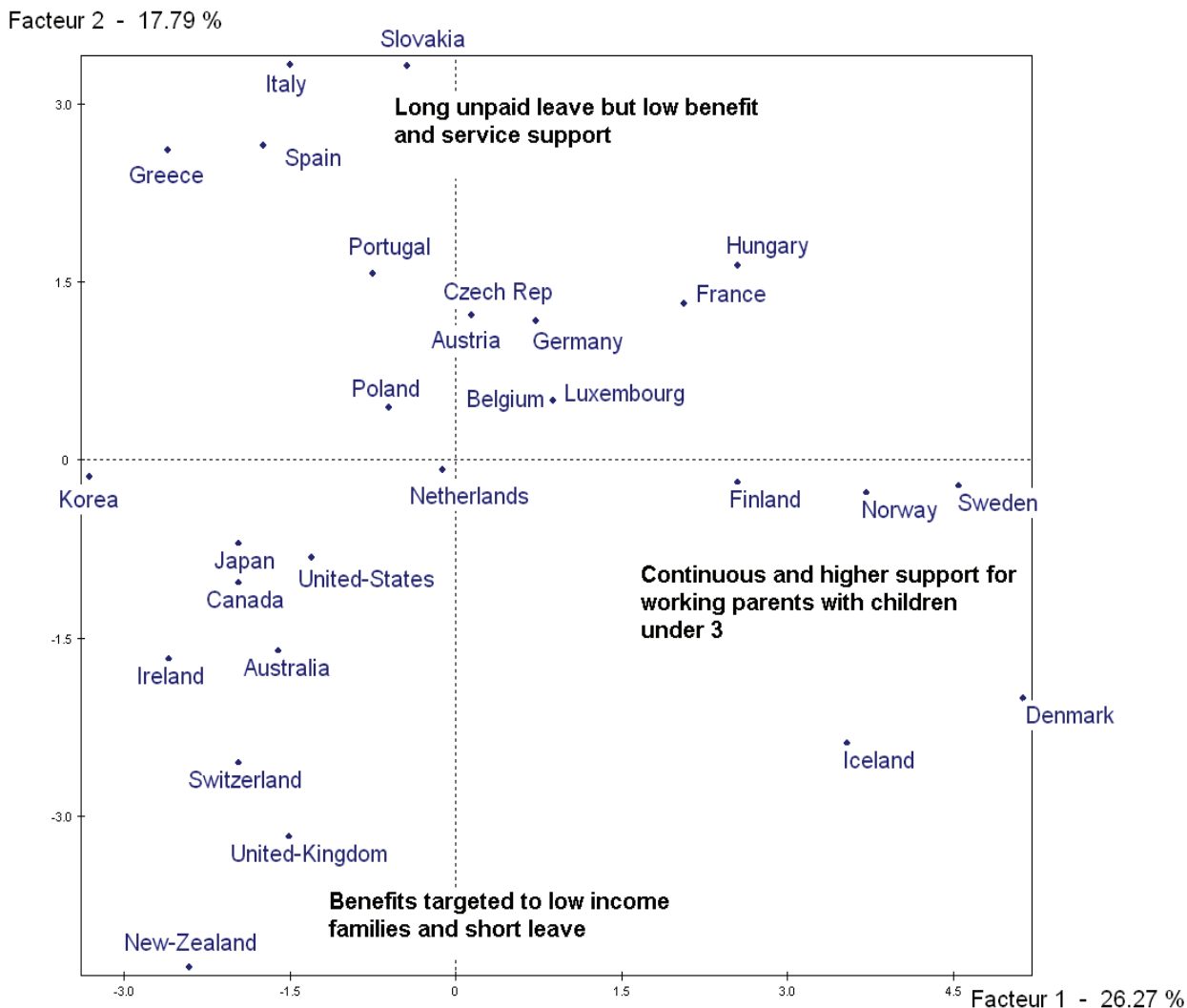

Source: Thévenon (2008).

\subsection{The Nordic countries: substantial support for families with young children}

Two distinct groups of countries stand out for the first focus of the PCA: the Nordic countries, on the right hand side of Figure 2, and the southern European and Anglo-Saxon countries on the left. That division can be attributed mainly to differences in the parental leave and child care systems for working parents with children aged under three. Parental leave in the Nordic countries is longer than in other countries: 53 weeks at the full-time equivalent of the average wage in Sweden and 47 weeks in Denmark, compared with only 27 weeks on average for all OECD countries (Table 1). The disparity can be attributed to a relatively high compensation in Nordic countries, since the length of leave is limited.

Full-time equivalent leave specifically reserved for fathers is also longer than in other countries: 13 weeks in Iceland and 11 weeks in Sweden, compared with 
an OECD average of only one week. However, paternity leave actually consumed only represents a tiny fraction of total parental leave, which is almost entirely taken by women. In all, the spending on leave is much higher in the Nordic countries, totalling on average $57 \%$ of per capita GDP for each child, versus $25 \%$ in the other countries, and only $4.7 \%$ in the Anglo-Saxon countries.

The percentage of children in formal child care is also much higher in the Nordic countries. Roughly half the children aged under three attend formal child care there, compared with less than one-fifth in the OECD countries as a whole. The amount invested per child is also much higher: on average \$5,758 in purchasing power parity in the Nordic countries, versus $\$ 2,520$ for the OECD average. However, the volume of cash benefits for families is below the average, and clearly targets low-income families.

The total investment in child care and education for all children aged under six is higher in the Nordic countries as well, at $1.8 \%$ of GDP on average, versus $0.7 \%$ in the other countries (and only $0.6 \%$ in the Anglo-Saxon and Asian countries, and $0.7 \%$ in southern Europe).

\subsection{Denmark: a model of a comprehensive family policy}

Denmark and Iceland stand out from the other Nordic countries (Figure 2), and partly for the same reasons: the percentage of children aged under three in formal child care is much higher in those two countries (62\% in Denmark and 59\% in Iceland). The level of spending on child care services is also higher in Denmark (2.3\% of GDP). The effective tax rate, i.e. the aggregate percentage of tax levied on earned income, is also much higher in Denmark-and in all Nordic countries - than in the other countries. That can be seen as the trade-off for the relatively high level of support granted as paid leave and child care services aimed at reconciling working and having young children. Denmark is probably the most developed model based on strong public intervention offering high, continuous support to enable parents to reconcile work and family. The system provides relatively high financial security during parental leave. Leave is relatively short but followed by easy access to formal child care then preschool and school. Consequently, the fertility rate is among the highest, with a particularly high (full-time equivalent) female employment rate. A high women's workforce participation nevertheless comes at the expense of a pronounced occupational segregation between men and women (Gilles and Terraz 2008).

\subsection{The Anglo-Saxon countries: support targeted on preschool-age children and poor households}

At the opposite end of the spectrum from the Nordic countries, the Anglo-Saxon countries, Japan, Korea and the southern European countries are in a similar position to each other, with generally lower support for reconciling work and 
children aged under three. There is little or no compensation during leave after the birth of a child. The supply of child care and education services is also generally lower, but there are sharp variations between countries. Public investment is also clearly targeted on preschool education. Public spending per child aged under three and attendance at child care facilities are much lower than for children aged three to six.

However, the Anglo-Saxon countries, plus Switzerland and Japan and Korea, differ from southern Europe in several respects, as illustrated by the vertical opposition between these two groups of countries in Figure 2. First, support for families through family benefits and tax breaks is much higher. It is actually the main form of intervention in those countries, where such support accounts for $1.9 \%$ of GDP, compared with $1.6 \%$ for the OECD average (the USA is an exception, with only $0.8 \%$ ). This support also clearly targets low-income families and has an objective of poverty reduction. A little more than one child in four (28\%) nevertheless attend formal child care, often private, compared with an OECD average of slightly fewer than one in four $(23 \%)$.

\section{$2.4 \ldots$ and a work/family balance based on labour-market flexibility}

In other words, the Anglo-Saxon countries are characterised by limited public support for reconciling work and children aged under three. Public investment is higher for preschool facilities for children aged three and over, usually on a parttime basis. The main objective is to provide preschool education to ensure equal opportunity for all children. In this context, the reconciliation of work and family life is fairly strongly based on the adjustment allowed by labour-market flexibility, i.e. the ability to change jobs without being unemployed for too long and especially the increase in part-time employment for women with small children. The work/family balance is therefore based on strong asymmetry between the positions of men and women in the labour market and implies that families with small children forego some income, which is not offset by public support. Family income is therefore often inadequate and family poverty rates are among the highest in these countries. Conversely, the adjustment made via the labour market enables these countries to maintain high fertility rates.

\subsection{Southern Europe: more limited assistance}

In the other countries, fertility and women's workforce participation rates are generally lower. They are especially low in most of southern Europe, where poverty rates are also higher. These countries are characterised by a 'deficit' of policies, whichever aspect is considered. The volume of cash benefits for families is very low. Parental leave can be relatively long, but uncompensated or poorly compensated. Portugal stands out from the rest of this group with slightly shorter 
parental leave, more targeted cash benefits for low-income families, and much higher attendance of children under three in formal child care: $23 \%$ in Portugal, versus less than $7 \%$ in Italy and Greece. Spain has almost the same low attendance at child care services, but much longer, unpaid parental leave.

The other countries, in eastern and central Europe, hold an intermediate position, except for France and Hungary, where indicators are far higher than average for all forms of family support. The length of parental leave equivalent to employment at the average wage there is longer than in most countries in central and eastern Europe. Above all, cash benefits for children are far less targeted on low-income families than in the other countries. The investment in child care services is also significantly higher than average, but attendance among children under three is much higher in France (29\%) than in Hungary (7\%).

\subsection{Eastern Europe: at the crossroads of diversity?}

Compared to the other three eastern European countries (i.e. the Czech Republic, Poland and Slovakia), Hungary provides more comprehensive support to parents with a young child through a balanced combination of policy support: parental leave payment compensation is higher (70 weeks of full-time equivalent against 39 in Poland and 35 in Czech Republic); public spending on child care services is also higher and their coverage for preschool children is also higher $(87 \%$ of children) than in Poland (36\%), for example; families are also supported through relatively generous financial benefits which sum to $2 \%$ of GDP compared to only $1 \%$ in Poland. However, the poorest families receive a relatively small share of this support compared to households earning two average wages. Slovakia is also in a remarkable position with a rather limited period of paid parental leave, while unpaid leave can be extended to three years. Investments in child care facilities are also relatively low despite higher coverage rates for children under age 2 than in other eastern European countries. As in Hungary, the level of family benefits is relatively high in percentage of GDP but does not appear to target poor families in particular. Thus, the combination of a long period of unpaid leave and the limited availability of other types of support make Slovakia comparable to most southern European countries. However, this situation is still quite specific in a geographical area where the development of family and child care policies has varied in its timing and followed different patterns (Szelewa and Polakowski 2008).

\section{Conclusion}

The development of increasingly detailed databases on family support makes it possible to access recent information to highlight more precise differences between countries than those established in the past between different welfare 
systems. In conclusion, it is worth noting some of the main limitations of these databases for comparing family support:

- First, the information available on family support primarily concerns support for families with children, on which the OECD database concentrates (at least initially). The period of early childhood is therefore fairly well covered, but data on support for families with older children are fairly rare and hard to obtain. However, in the context of an ageing population, in future these databases should not only cover support for families with children as comprehensively as possible, but also support for families that have to care for dependent elderly members.

- The comparison of policies can also be biased by the fact that local support is only rarely taken into account, even though it has had a considerable and growing impact in some countries in recent years.

- Similarly, knowledge of support financed by companies is only partial, even though companies are actors whose importance is more and more broadly recognised.

- Finally, and this may be the biggest problem with the databases on family policies, the available information concerns only support offered, not policy takeup, i.e. to what extent the mechanisms are actually used. The difficulty in estimating the use of parental leave is a good illustration of this problem: while administrative statistics can be used to estimate the number of people taking parental leave, it is generally more difficult to estimate the 'eligible' population. However, being able to compare actual policy take-up more effectively is a key to better assessing their effects on fertility and other behaviour.

\section{References}

De Hénau, J., D. Meulders, and S. O’Dorchai. 2006. "The childcare triad? Indicators assessing three fields of child policies for working mothers in the EU-15." Journal of Comparative Policy Analysis 8(2): 129-148.

Esping-Andersen, G. 1999. Social Foundations of Postindustrial Economies. Oxford, Oxford University Press.

Gauthier, A. H. 2002. "Family policies in industrialized countries : Is there convergence?" Population-E 57(3) : 447-474.

Gilles, Ch. and I. Terraz. 2008. "Réduire la segmentation hommes/femmes du marché du travail en Europe : quels leviers d'actions?" Note de veille du Centre d'Analyse Stratégique 92, March.

Gornick, J. and M. Meyers. 2003. Families that Work. Policies for Reconciling Parenthood and Employment. New York, Russell Sage Foundation.

Gornick, J., M. Meyers, and K. Ross. 1997. "Supporting the employment of mothers: policy variation across fourteen welfare states." Journal of European Social Policy 7(1): 45-70.

Math, A. and O. Thévenon. 2008. "Comparing and assessing family policies: scope and limits of available expenditure database.” EU Conference on Policies for Today's 
Families: Towards a Framework for Assessing Family Policies in the EU, 25 June, «http://ec.europa.eu/employment_social/spsi/seminar_policies_2008_en.htm».

Neyer, G. 2006. "Family policies and fertility in Europe." MPIDR Working paper WP 2006-10.

Meulders, D. and S. O'Dorchai. 2007. "The position of mothers in a comparative welfare state perspective." In: Del Boca, D. and C. Wetzels (eds.) Social Policies, Labour Markets and Motherhood. Cambridge University Press, pp. 3-27.

OECD. 2007. Babies and Bosses: Reconciling Work and Family Life. A Synthesis of Results. Paris.

Szelewa, D. and M. Polakowski. 2008. "Who cares? Changing patterns of childcare in Central and Eastern Europe.” Journal of European Social Policy 18(2): 115-131.

Spielauer, M. 2004. "The Contextual Database of the Generations and Gender Program: overview, conceptual framework and the link to the Generations and Gender Survey." MPIDR Working paper WP 2004-014.

Thévenon, O. 2008. "Family policies in developed countries: contrasted patterns." Population \& Societies 448, September.

Thévenon, O. 2007. "Family policies in OECD countries: from (balanced) objectives to (mixed) means?" EAPS Conference, Barcelona.

Thévenon, O. 2006. "Régimes d'Etat social et convention familiale: une analyse des régulations emploi-famille." Economies et Sociétés 27(9) : 1137-1172. 


\section{Appendix: Available databases for the analysis of policies supporting families and their impact on fertility}

To study these differences in policy, several databases are available in addition to the OECD Family Database presented above. The data can be used to compare various aspects of family support over different periods, depending on the reconstituted time series. Some of the databases include socio-demographic contextual data as well as indicators on support programmes to allow comparisons of different configurations of family policies, their context and their outcomes. The EDACwowe website (http://www.edacwowe.eu/), developed by the EU "Reconciling Work and Welfare in Europe" Network of Excellence, draws on most of the information sources available at national and international level to compare employment and welfare systems in Europe. The site lists the sources of socio-demographic data, information on public opinion, and policies or institutions that deal with income and benefits, work and employment, care and living standards. Below is a short description of the main databases available on family policy.

The website of the Clearinghouse on International Developments in Child, Youth and Family Policies at Columbia University (http://childpolicyintl.org/) comprises information on benefits and services for families in 23 industrialised countries. There are also data on population trends, social indicators, including child welfare, and information on support for the work/family balance.

Two other databases on family policies have been released by the Luxembourg Income Study (LIS). One database describes policies to reconcile work and family as observed in 14 countries in the mid-1980s (http://www.lisproject.org/publications/fampol/fampolaccess.htm). That database was used by Janet Gornick, Marcia Meyers and Katherin Ross (1997) to compare support for working mothers. The other database is an update of the first one to the early 2000s in 12 countries (covering northern Europe, continental Europe, the UK, Canada and the USA). It contains much more detailed information about parental leave, child care attendance and a special module on work-time legislation. Gornick and Meyers (2003) used these data to compare policies favouring the work/life balance. The LIS also proposes six waves of harmonised microdata covering some 30 countries in 2004 on household structure, socioeconomic status, income and income structure (percentage of welfare benefits in income).

The University of Calgary has also set up a comparative database that includes information about cash benefits, the associated public spending, parental leave, and population and employment trends (http://www.soci.ucalgary.ca/FYPP). The database covers 22 OECD countries and proposes annual time series for the years 1970 to 2000. Anne Gauthier (2002) used these data to show that, in 2000, benefits and leave policies were more heterogeneous within a group of countries than they were in the early 1980 s. 
The Generations and Gender Programme steered by the United Nations Economic Commission for Europe also includes the creation of a contextual database to round out surveys of individuals with a set of detailed information about the economic and institutional context. The information gathered covers demographic and economic contexts, the labour market, family policies, including support for child care or care for elderly dependents, the tax system and the pension system. More qualitative information on political systems is provided as well. The advantage of this context database is that it contains detailed information at regional level, and time series permitting a 'multi-level' analysis (Spielauer 2004). It also gives access to information on eastern European countries that is otherwise difficult to obtain. However, the number of countries covered by the database is limited (Bulgaria, Georgia, Hungary, Lithuania, Poland, Norway, Romania, Russia and France in 2008).

In addition to the information available in these databases, more precise data on family policy spending are available in the European System of Integrated Social Protection Statistics database (ESSPROS) coordinated by Eurostat. The data available can be usefully rounded out with qualitative information on social protection systems regularly updated by the European Social Protection System in Member States (MISSOC): http://ec.europa.eu/employment_social/spsi/missoc_en.htm. Covering the 27 member countries of the European Union, this harmonised base of welfare accounts provides information about the amounts spent on support for child care, parental leave and cash benefits for families. The main advantage of this database is that it offers updated harmonised data, which can be used to reconstitute time series starting in the early 1980s. However, there are gaps because some expenditure items are hard to classify and because some types of family support are left out. In particular, the data on support provided at local—as opposed to national - level, financial benefits provided through the tax system, or spending on preschool education are not always complete, and the comparisons based on them can be skewed (Math and Thévenon, 2008). To round out those data, the Family Database being developed at the OECD includes estimates of these items in the set of indicators concerning family support policies. 